\title{
Courtesy and I dleness: Gender Differences in Team Work and Team Competition
}

\section{Radosveta I vanova-Stenzel* Dorothea Kübler**}




\title{
Courtesy and Idleness: Gender Differences in Team Work and Team Competition*
}

\author{
Radosveta Ivanova-Stenzel ${ }^{\dagger}$ \\ Humboldt University Berlin \\ Dorothea Kübler \\ Technical University Berlin and IZA, Bonn
}

September 21, 2005

\begin{abstract}
Does gender play a role in the context of team work? Our results based on a real-effort experiment suggest that performance depends on the composition of the team. We find that female and male performance differ most in mixed teams with revenue sharing between the team members, as men put in significantly more effort than women. The data also indicate that women perform best when competing in pure female teams against male teams whereas men perform best when women are present or in a competitive environment.
\end{abstract}

Keywords: team incentives, gender, tournaments

JEL classification numbers: C72; C73; C91; D82.

\footnotetext{
*For helpful comments we thank Dirk Engelmann, Bernd Irlenbusch, Lydia Mechtenberg, Wieland Müller, Julia Schmid, Georg Weizsäcker, and participants at the GEW Meeting 2005 in Köln and the First Annual IZA Workshop on Behavioral and Organizational Economics 2005 in Bonn. Financial support by the Deutsche Forschungsgemeinschaft (DFG) through SFB 649 "Economic Risk" is gratefully acknowledged.

${ }^{\dagger}$ Department of Economics, Spandauer Str. 1, 10178 Berlin, Germany. E-mail: ivanova@wiwi.huberlin.de.
}

${ }^{\ddagger}$ Department of Economics and Management, Straße des 17. Juni 135, 10623 Berlin, Germany. Email: d.kuebler@ww.tu-berlin.de (corresponding author). 


\section{Introduction}

When setting up team work in a firm, the question arises of how to group workers into teams. Should they be of the same ability, gender, temperament or should they differ in some or all of these characteristics?

In this paper we report on a real-effort experiment to investigate the relevance of gender for the optimal composition of a team. In order to address this question, we study the performance of mixed teams versus teams consisting of men or women only. We hypothesize that the gender of team members matters for team performance because social relations are important in team work. For example, a person's effort choice can be affected by the relationship to those with whom he or she shares the returns from this effort. Also, free-riding incentives can be significantly reduced by peer pressure, altruism, or loyalty among group members. ${ }^{1}$ Moreover, social norms and gender stereotypes may influence the behavior of men and women in teams.

We also design our experiments to establish whether the composition of a team affects performance under different incentive schemes differently. Apart from simple team pay we study competition between teams where the team with the highest performance wins a bonus. We investigate whether men and women react differently to monetary incentives and how interactions between men and women affect their performance under the two different incentive contracts. For the experiment, teams consisting only of men, teams consisting only of women and mixed teams consisting of men and women are formed. In one treatment, male teams compete with male teams, in another treatment female teams compete with female teams, in a third treatment male and female teams compete with each other, and in a fourth treatment we introduce competition between mixed teams. Thereby, we are able to evaluate whether the gender composition of one's own and the competing team matters.

\footnotetext{
${ }^{1}$ The role of social pressure in team work is discussed by Kandel and Lazear (1992) and Huck, Kübler, and Weibull (2004). For loyalty and altruism in a model of team production see Ferreira (2002).
} 
Our main results suggest that performance does not exclusively depend on the chosen incentive scheme (team pay versus team competition), but rather on the gender of the group members in conjunction with the chosen incentive scheme. Men exert higher effort when paired with women or in a competitive environment than when they are among themselves. Women perform best in pure female teams when competing against male teams and perform worst under revenue sharing in mixed teams.

The remainder of the paper is organized as follows: In the next section we give a brief overview of the relevant literature. In Section 3 the design and experimental procedures are introduced. In Section 4 we present and analyze the results of our study and relate them to previous findings from other studies in more detail. Section 5 concludes.

\section{Review of the literature}

The optimal composition of teams has only recently been studied by economists. Ferreira (2002) develops a model of team composition when the principal can choose both the incentive contract and the degree of diversity among team members. His theory is tested in a companion paper (Adams and Ferreira, 2003), using the gender composition of corporate boards. It is observed that the more heterogeneous a board (i.e. when women are present), the more high-powered the incentives. This is consistent with homogeneity or loyalty being complementary to monetary incentives. Hehenkamp and Karbøe (2004) analyze optimal incentive contracts of a team that is heterogeneous with respect to ability, in the presence of peer pressure. They show that the principal provides agents of low productivity with stronger incentives than agents of high productivity. This is due to the fact that peer pressure (arising from unequal effort levels) is costly for the principal.

Both field and laboratory experiments have been used to demonstrate that competition can increase the output of a team significantly. Nalbantian and Schotter (1997) compare team competition to team work in an experiment where effort choice creates a monetary cost. Erev et al. (1993), and van Dijk et al. (2001) use real effort experiments, the 
former to study team competition, the latter to study team work compared to individual incentive schemes. However, none of the papers deals with issues of gender and optimal team composition.

The experimental literature on gender effects is extensive. The main insights for gender differences have been gained by testing subject's behavior in public good, prisoner's dilemma, ultimatum and dictator games. One important aspect of such experiments is whether participants are aware of the gender of the other player(s). Nowell and Tinkler (1994) conclude from previous studies that "gender differences would seem to be more forcefully expressed in environments in which the gender of the other subjects is known". ${ }^{2}$ In our experiments, participants can observe the gender of other participants, and we will therefore focus on experimental studies of this type. ${ }^{3}$

In Nowell and Tinkler's (1994) study of public good games, all-female groups are slightly more cooperative than all-male groups and mixed groups. Ortmann and Tichy (1999) observe in their study of the prisoner's dilemma game that in mixed-sex settings, women cooperate significantly more often than men in the first round. ${ }^{4}$ However, this difference

\footnotetext{
${ }^{2}$ This is based on the results in Rapoport and Chammah (1965) and Mason et al. (1991). Both experiments study prisoner's dilemma situations, but only the former with known rivals (finding that women are less cooperative than men in single-sex situations) while in Mason et al. gender is not known and no gender differences can be observed. Also, Wiley (1973) finds that in a mixed-sex prisoner's dilemma situation without gender identification, there is no significant difference between the three possible gender combinations whereas with verbal communication (and thus gender identification) cooperation rates are significantly higher in mixed-sex than in single-sex settings.

${ }^{3}$ For example, in the work by Andreoni and Vesterlund (2001) and Eckel and Grossman (1998) subjects did not know the gender of their opponents. A number of papers, e.g. Cadsby and Maynes (1998), are hard to classify, because it is not mentioned whether participants were able to observe the gender of others.

${ }^{4}$ Subjects know the gender of the other player only in the single-sex treatments, not in the mixed-sex treatments, where they only know that they are either paired with a man or with a woman. This is analogous to our design, as described in the next section.
} 
decreases after a number of rounds. For single-sex games, there is no significant gender difference, and the difference between male and female behavior in mixed-sex environments disappears if one controls for past experience. Andreoni and Petrie (2004) study beauty and gender in a repeated public goods game where subjects are identified with the help of photographs. In their experiment, women make more money than men when no information about previous contributions is provided. However, if this information is included, men contribute more and also induce others to make higher contributions, which leads to higher payoffs for men than for women.

Gender effects in ultimatum games have been studied by Eckel and Grossman (2001) whereas Dufwenberg and Muren (forthcoming) ran experiments with dictator games. In both studies, players were aware of the gender of the other player, and it emerges that behavior is influenced by this information. Eckel and Grossman (2001) find that offers of women are more generous than those of men, that offers of women do not depend on the partner's gender, and that they are more likely to be accepted. Dufwenberg and Muren (2002) observe that women are treated more nicely than men in the dictator game.

Finally, Gneezy et al. (2003) as well as Niederle and Vesterlund (2005) study the interaction of gender and competition, but their experiments are based on individual compensation, not on team work. Gneezy et al. (2003) find that men react positively to tournament-style incentives while women increase their performance only when they compete with women. In Niederle and Vesterlund (2005) there is no difference between the performance of men and women in a competitive environment, but when given the choice, women prefer not to compete.

A great number of psychological studies have been conducted to evaluate gender differences in helping behavior, cooperation, competitiveness as well as in performing memory tasks. A number of these studies will be discussed below. We will relate the results of our study to the findings of the economics and the psychology literature in greater detail in Section 4. 


\section{Experimental design and procedure}

In order to test for gender and incentive effects in an appropriate environment, participants worked on a real task. They had to solve as many memory games as possible within 15 minutes. ${ }^{5}$ We used memory games posted on the web, consisting of ten pairs of cards. At the start of the game, 20 cards with their faces down are shown. Two cards have to be clicked on. Then a "Check It"-button has to be pressed, and if the cards match, they are automatically removed. Otherwise, a "Pick again"-button has to be pressed and two more cards can be selected. The game ends when all pairs have been matched. ${ }^{6}$

In the experiment, when a participant had solved a game completely, he or she raised her hand, we recorded the solved game on the personal record sheet and opened a new game for this participant. The website offers 10 different games (with pictures of dinosaurs, colors, bugs, animals, musical instruments, etc.). In order to prevent confusion from recalling games played previously, we opened a new game with different cards every time. In all sessions, we started with the same game (dinosaurs) and used the same order of games.

Each team consists of two members. We varied the composition of teams with respect to gender. In addition, two different incentive schemes were used, revenue sharing and team competition. Payoffs in the revenue sharing treatments (RS) were computed by adding the number of solved games of the two team members (called "points" in the instructions), dividing the sum by two and paying out the resulting number in Euros

\footnotetext{
${ }^{5}$ We chose the memory game for a number of reasons. First, a more realistic setting might import interpretations and perceptions which are neither controlled nor relevant considering the specific question explored. Also, solving memory games captures some key elements of real work - it is an absorbing and demanding task that requires full concentration. Furthermore, output is exactly measurable. And comparisons with previous experimental studies are possible which have already provided a number of stylized facts concerning gender specific behavior in memory tasks.

${ }^{6}$ The website can be found at http://www.funbrain.com/match/.
} 
to each team member. In the team competition treatments (TC), the number of solved games by both team members was computed. Then, the number of solved games of a team was compared to the number of solved games by a randomly selected second team. The team that had solved more games received a bonus of 4 points (=Euros), and for the losing team we subtracted 4 points from the number of games solved jointly. Each team member then received points equal to the number of games solved in the team plus or minus the bonus, divided by two. If both teams had solved the same number of games, no points were subtracted or added.

\begin{tabular}{clccc}
\hline Treatment & \multicolumn{2}{l}{ Composition of Teams } & \# Sessions & \# Observations \\
\hline Revenue Sharing (RS) & Single-Sex Teams: & Male & 2 & 24 \\
& & Female & 2 & 24 \\
& Mixed Teams & & 2 & 24 \\
\hline Team Competition (TC) & Single-Sex Teams: & Male & 1 & 12 \\
& & Female & 1 & 12 \\
& & & 2 & 24 \\
& Female Teams vs. Male Teams & 2 & 24 \\
\hline All & Mixed Teams & 12 & 144 \\
\hline
\end{tabular}

Table 1: Experimental Treatments

Altogether, we ran seven different treatments: pure male teams with revenue sharing; pure female teams with revenue sharing; mixed teams (one man and one woman) with revenue sharing; competition between pure male teams; competition between pure female teams; competition of female against male teams; and competition between mixed teams. Table 1 summarizes the treatments. Each session had 12 participants. Overall, we collected 144 independent observations from 144 participants.

The participants in each session were seated in two groups of six persons at opposing walls of the computer lab. When participants entered the lab, the chairs were positioned such that the two groups faced each other. Only after the participants had read the instructions we told them to turn around and face the computer in the corresponding booth. This ensured that all participants had enough time to notice the gender composition on both 
sides of the room. In the instructions, ${ }^{7}$ participants were informed that they had been randomly matched with a person sitting at the same side of the room. These two participants formed a team. In the sessions with teams consisting only of men or women, we made sure that only male or female participants were seated on either side of the room. ${ }^{8}$ Thus, the information that they were randomly paired with a participant from their side of the room implied that it was a person of their own gender. But we never explicitly mentioned gender in order to test for the relevance of gender without directly pointing out this aspect of the situation to the participants. In the treatment with mixed teams, three men and three women were seated on each side of the room. Thus, participants knew that they might be paired either with a man or a woman.

In the treatments with team competition, we additionally informed participants that the competing team consists of persons placed at the opposite side of the room. For competition between men or women only, we invited either only men or only women to the experiment. For competition between male and female teams, we invited six men and six women and placed them at opposite sides of the room. For competition between mixed teams, we again invited six men and six women, but placed them at both sides of the room, i.e. three men and three women were seated on each side of the room. Thus, participants could see each other and they could figure out the gender composition of both, one's own and the competing team.

At the end of the experiment all participants were informed about the number of games solved by their team and, in the team competition treatments, whether their team received a bonus of 4 points, no bonus or whether their team payoff was decreased by 4 points. There was a show-up fee of 3 Euros. Average earnings in the experiment which lasted about 40 minutes were 8.14 Euros (including the show-up fee).

\footnotetext{
${ }^{7}$ See the Appendix for a translated version of the instructions. The original instructions (in German) are available upon request from the authors.

${ }^{8}$ In all treatments where men and women were present, we ensured the correct distribution of men and women in the room by handing out seat numbers for the computer terminals to the participants when they entered the room. Subjects picked these numbers themselves from a stack of cards, but we manipulated from which stack they drew a card. This went unnoticed by the participants.
} 


\section{Results}

The results are organized around three research questions: (1) Do different payoff schemes for team work affect the performance of men and women? (2) Are there gender differences in performance under different payoff schemes? (3) Do male and female performance depend on the composition of the team? We will answer these questions by performing statistical tests on the experimental data. For the tests, the dependent variable is the number of games solved by a participant. Since our independent variables, gender and incentive contract, can each take only one of two values, the statistical analysis of the data is performed on the basis of the two-sample t-test (henceforth: t-test) as well as the non-parametric Mann-Whitney $U$-test (henceforth: MWU-test).

\subsection{Performance of men and women under different payoff schemes}

First we compare overall performance under the two payoff schemes (RS and TC). According to Table 2 the average result in the TC treatments (5.32) is slightly higher than the average in the RS treatments (5.03). This is also true for each subgroup. Men as well as women solve on average more memory games in the TC than in the RS treatment (men: 5.67 vs. 5.33 ; women: 4.97 vs. 4.72 ). However, these differences are not significant. ${ }^{9}$ Thus, the chosen payment scheme does not significantly influence the average individual performance. But the switch from revenue sharing to team competition increases the variance of outcomes (see Figure 1). The null hypothesis of no differences in variance between both treatments is rejected in favor of the alternative hypothesis of a higher variation in the TC treatment at the $5 \%$ level (Variance Ratio F-test, $p=0.0355$ ). ${ }^{10}$

\footnotetext{
${ }^{9}$ We find that $p>0.15$ for each subgroup (males, females) as well as for the pooled data, regardless of the statistical test used.

${ }^{10}$ The statistical significance of this result on subgroup level is maintained only for the male subgroup.
} 


\begin{tabular}{lcccccccc}
\hline & \multicolumn{3}{c}{ Revenue Sharing (RS) } & \multicolumn{3}{c}{ Team Competition (TC) } \\
& Mean & Min. & Max. & Std. Dev. & Mean & Min. & Max. & Std. Dev. \\
\hline Men & 5.33 & 3 & 7 & 0.956 & 5.67 & 3 & 9 & 1.454 \\
Women & 4.72 & 2 & 7 & 1.210 & 4.97 & 2 & 7 & 1.383 \\
All & 5.03 & 2 & 7 & 1.126 & 5.32 & 2 & 9 & 1.452 \\
\hline
\end{tabular}

Table 2: Descriptive statistics: Number of Solved Games

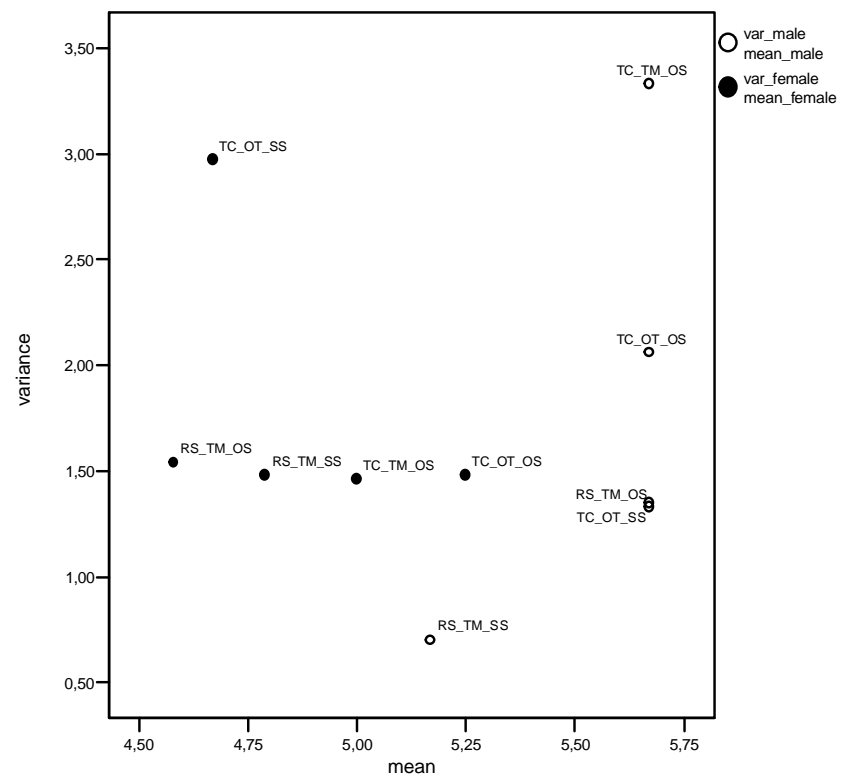

Figure 1: Mean-variance scatterplot of male and female performance. We distinguish between team members being of the same sex (TM_SS), of the opposite sex (TM_OS) and the members of the other team being of the same sex (OT_SS) or of the opposite sex (OT_OS). E.g., RS_TM_SS summarizes the data from the revenue sharing treatment where the team member was of the same sex; empty dots stand for women, full dots for men.

Observation 1: The choice of payoff scheme (revenue sharing vs. team competition) does not significantly influence individual performance. However, competition significantly increases the variance of the observed outcomes.

The incentive scheme alone has no clear-cut effect on performance. This allows us to focus on gender effects and in particular on the interaction of gender with the chosen incentive 
scheme. Of course, the sensitivity of performance to incentives depends on the chosen task. For our purpose of investigating gender effects we have succeeded in identifying a task in which performance is not very sensitive to monetary incentives alone, but possibly to the incentive scheme in conjunction with gender (as will be shown below).

A number of studies find a positive effect of competition on performance, see, e.g., Nalbantian and Schotter (1997), van Dijk et al. (2001), Gneezy et al. (2003), and Erev et al. (1993). However, each of these studies differs from ours in several respects. In van Dijk et al. (2001) and Gneezy et al. (2003), for example, single individuals compete instead of teams as in our case. Nalbantian and Schotter (1997) do not use a real effort task but have participants pick a number for their effort choice, where higher numbers are associated with a higher monetary cost. Erev et al. (1993) consider team competition in a real effort environment as we do, but participants were able to observe the performance of the competing team as well as of the other members of their own team constantly during the experiment. Thus, they had the possibility to increase effort in response to the performance of others, which might enhance the effectiveness of competition. In addition, Nalbantian and Schotter (1997) and Erev et al. (1993) split the teams (consisting of six respectively four participants) who first work together under revenue sharing into two competing teams. Thus, by introducing competition between teams the team size is decreased, leaving it open whether the increase in performance can be ascribed to competitive pressure or to smaller team size. Also, they did not control for the composition of teams in terms of gender as a possible determinant of performance.

The outcomes of team competition show a greater variance than the outcomes of revenue sharing, which is in line with the findings of Nalbantian and Schotter (2003) as well as van Dijk et al. (2001). In a competitive environment, the optimal strategy depends on the ability of one's competitors. Thus, different beliefs might lead to different optimal strategies in the case of competition, which explains the increased variance in the number of solved games compared to revenue sharing. 
The increased variance of payoffs under team competition could affect the performance of men and women differently, given the different degrees of risk aversion of men and women (as evidenced in the psychology literature (Byrnes, Miller and Schafer, 1999) and in the economics literature (Eckel and Grossman, forthcoming)). However, as stated in Observation 1, men and women do not react in a significantly different way to competition and thus to the higher variance in payoffs. This finding is consistent with the result of Gneezy et al. (2003) who do not find any evidence that risk aversion influences male and female performance in the context of tournaments.

\subsection{Does gender influence performance?}

If men and women are equally skillful and incentives are the same for both groups, the average number of games solved should not be significantly different. However, the observed outcomes reveal a strong gender effect on performance (see Table 2), indicating that men solved significantly more games than women. ${ }^{11}$ In addition, this result holds for both payoff schemes and is statistically significant (t-test, RS: $p=0.02$, TC: $p=0.042) .{ }^{12}$

Observation 2: Men perform significantly better than women.

Differences in performance between women and men depend on the specific task. ${ }^{13}$ Our memory task reveals a clear asymmetry in that men solve on average more games than women. This allows us to study team work in the presence of team members with different abilities.

\footnotetext{
${ }^{11}$ MWU-test: $p=0.003$, t-test: $p=0.002$.

${ }^{12}$ The corresponding $p$-values for the MWU-test are: $p=0.015$ for RS and $p=0.063$ for TC, revealing only a weakly significant difference for the team competition treatment.

${ }^{13}$ For example, in Gneezy et al. (2003) where subjects had to solve mazes, men also performed better than women. In Niederle and Vesterlund (2005) no gender difference can be found for the task of adding numbers.
} 
Although the memory game itself is not the main focus of this paper, it is interesting to compare our results to other studies based on this game. Several experiments by psychologists show that women outperform men in the memory game (see, e.g., Tottenham et al., 2003, McBurney et al., 1997). However, no monetary incentives were used in the psychology experiments, and performance in these studies was measured in other ways than in our experiment. ${ }^{14}$ The difference to our findings can be due to the interaction of gender with other features of the situation such as monetary incentives. E.g., women might be overall less motivated than men in a situation where they get paid according to performance. While our data are not sufficient to fully explain the observed difference, we will address the relationship between incentives and gender in the next section.

\subsection{Gender effects with revenue sharing}

A number of factors can affect behavior of men and women depending on whether they face a team member of the same or of the opposite sex. With revenue sharing and assuming that the utility of participants is linear in money, the expected number of games solved by the other team member should not affect performance. Thus, even if men or women believe that the other gender differs in ability, this should not affect choices. But when working together in a team, motives such as solidarity, courtesy, competitiveness, or indifference towards the same or the opposite gender can come into play. Also, social norms regarding helping behavior between men and women might change a subject's motivation to contribute when participating in a mixed team compared to a single-sex male or female team.

As shown in Figure 2 for revenue sharing (RS), there are no significant differences between male and female performance within single-sex teams (5.17 vs. 4.79). However, in mixed

\footnotetext{
${ }^{14}$ Only one game is solved and performance refers either to the "efficiency measure" defined as the total number of trials divided by total time (Tottenham et al., 2003) or to the "memory score" defined as the total number of times any card was turned over (McBurney et al., 1997).
} 
teams men solve on average 5.67 games, as compared to 4.58 for women (t-test, $p=$ 0.037). ${ }^{15}$ The considerable difference between effort of men and women in mixed teams is due to the strong increase of male performance relative to single-sex male teams (MWU, $p=0.052$, one-tailed). Men increase their effort by $10 \%$ when paired with a woman instead of a man. Women not only fail to increase their effort when paired with men, but the number of solved games slightly decreases on average (4.79 vs. 4.58 in favor of purely female teams).

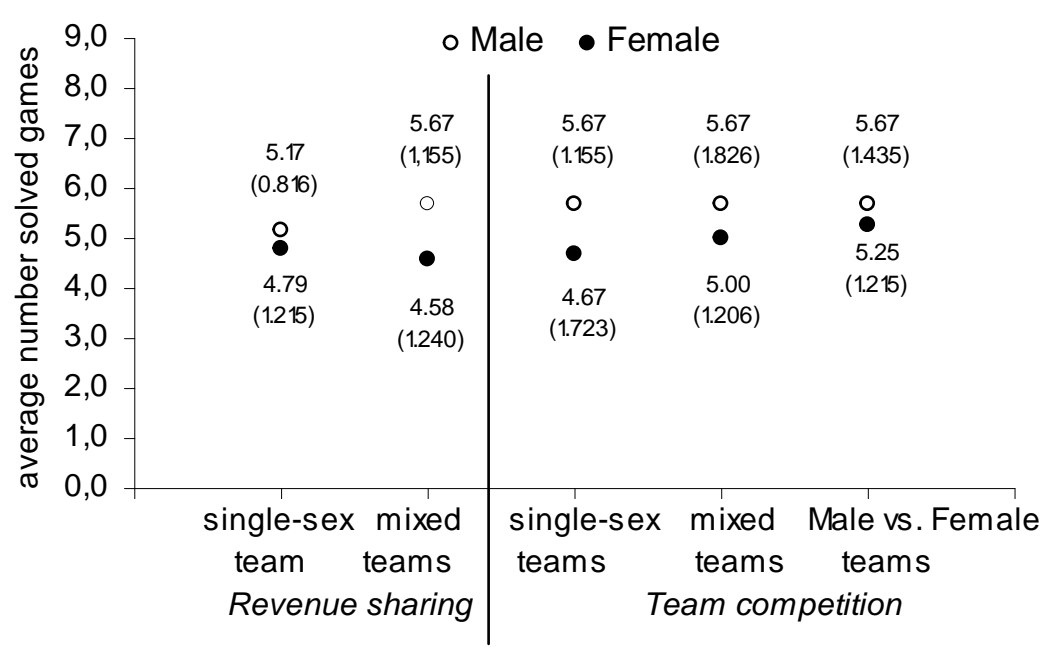

Figure 2: Average performance of men and women in all treatments (standard deviations in parantheses)

This leads to:

Observation 3: With revenue sharing (RS), the performance of men and women does not significantly differ in the case of single-sex teams. However, in mixed teams men perform significantly better than women.

The behavior of men and women is consistent with the gender stereotypes that men should support women and women need to be helped. When paired together in a team, men adopt the active role while women are more passive than in situations where only

\footnotetext{
${ }^{15}$ The corresponding value for the MWU-test is $p=0.033$.
} 
women are present. This finding is in line with psychological experiments on helping behavior. They demonstrate that women are overall more likely to receive help than men. Furthermore, men display chivalry and helping behavior towards strangers (comparable to our experimental setting with anonymity) while women typically care for friends and intimate relations. ${ }^{16}$

As mentioned in the brief review of the literature, Eckel and Grossman (2001) find that men are chivalrous when playing ultimatum games in that they are more likely to accept offers from women. Dufwenberg and Muren (forthcoming) observe that women receive higher donations than men in dictator games, and in the experiment by Andreoni and Petrie (2004) women earn more in public good games. These observations are similar to our finding that men behave nicely towards women when working together in a team. Eckel and Grossman (2001) also find that in ultimatum games, women almost never reject offers made by women, which they call solidarity. Solidarity or loyalty among women can explain our finding that women exert higher effort when the benefits are shared with another woman rather than with a man. Finally, the study of Wiley (1973) on prisoner's dilemma games shows that men cooperate significantly more often when paired with a woman than when paired with a man.

To sum up, our results reveal a significant gender difference in performance in mixed teams which is not present in single-sex teams. This difference in behavior in mixed teams is consistent both with the results from other experiments and with common gender stereotypes.

\subsection{Gender effects with team competition}

Economic theory predicts that own ability and the ability of one's opponents in a tournament affect the optimal effort choice. Thus, men who think (correctly) that they are on average better in solving memory games than women might be tempted to reduce their

\footnotetext{
${ }^{16}$ For an overview and a meta-analysis of this literature see Eagly and Crowley (1986).
} 
contribution when competing against a female team. Also female (less able) teams may lower their effort when competing against male teams, suspecting that their team will lose anyway. A similar effect could be generated by the stereotype that women perform poorly in a competitive environment. On the other hand, solidarity among women might increase women's performance when competing against men.

In the data, competition among single-sex teams leads to a gender gap in mean performance when the competing teams are of the same sex (5.67 vs. 4.67 in favor of the men), but this difference is not significant ( $p>0.10$ regardless of the statistical test used). Furthermore, as shown in Figure 2 the gender gap almost disappears when male and female teams compete against each other (the average number of solved games is 5.67 and 5.25, respectively). There is a noticeable although statistically insignificant rise in women's average performance from 4.67 (competition of female against female teams) to 5.25 (competition of female against male teams). Furthermore, as shown in Figure 2, the performance of men in team competition does not significantly depend on the composition of both, the own and the competing team. The performance of women in team competition with mixed teams is inbetween the performance of single-sex teams and male vs. female teams. ${ }^{17}$ This result is in line with our previous findings of lower performance of women in mixed teams and higher performance of women when competing against men.

Observation 4: With team competition (TC), the composition of the team has no significant effect on the performance of men and women. There is a tendency for women to increase their effort when competing in pure female teams against pure male teams.

The prediction that all teams will lower their performance when male and female teams compete is not supported by the data. Rather, we observe that women perform best when competing against men, which is consistent with the hypothesis that there is a certain

\footnotetext{
${ }^{17}$ There is no significant difference between mean performance of men and women when they compete in mixed teams ( $p>0.3$ in both statistical tests).
} 
degree of solidarity among women. Gneezy et al. (2003) find for incentive schemes based on individual performance that women perform better when competing against women than against men. However, a number of studies by psychologists based on game-playing by children show that girls are more competitive when playing against boys than against girls, see Moely et al. (1979) and the studies cited therein as well as Conti et al. (2001). Erev et al. (1993) observe (for mixed teams) that the performance enhancing effect of competition diminishes as the difference in ability between the competing groups increase. This is consistent with the predictions of the theory. In our experiment, the performance of the more able single-sex male teams is independent of the gender of the competing team, and women even increase their performance slightly when competing against men. Thus, the (negative) incentive effect due to differences in ability might be overcompensated by gender effects in our experiment.

\section{Conclusions}

This paper reports on an experiment about group incentives and productivity, focusing on the relevance of gender for the optimal composition of a team. We set up an environment in which we can measure the effects of changes in the gender composition and the incentive scheme on performance. For this purpose we conduct an experiment in which participants have to solve a real task.

The results of the experiment suggest that gender plays a role in the context of team work and is an important aspect for the optimal composition of teams. In particular, we find that performance does not simply depend on the chosen incentive scheme, but rather on the gender of the group members in conjunction with the chosen incentive scheme. For example, the performance of women can be increased by $15 \%$ when moving from revenue sharing in mixed teams to team competition between single-sex male and female teams. The data also show that, holding the incentive scheme fixed, the gender composition of the team matters for team work (RS), but not for team competition (TC), especially 
for men. This can be due to the fact that by introducing a tournament among teams, the focus of attention is shifted from the gender aspect of the situation to the aspect of competition.

Which incentive scheme and which gender composition of team members maximize the performance of a team? Men perform worst when the benefits are shared with another man in a cooperative environment. Either the presence of women or competition or both lead to a significant increase in male performance. ${ }^{18}$ The case is quite different for women. They tend to reduce their effort when paired with men in case of team pay, and perform best when competing against men. ${ }^{19}$ Therefore, our experiment yields a number of suggestions for the organization of work in a situation with team work and a task that exibits similar features as the chosen memory game. If the work force consists only of men, it would be best to introduce competition among teams. Alternatively, hiring women in such a situation increases the performance of men, but may decrease overall performance due to the weak performance of women in mixed teams with revenue sharing. If the workforce consists only of women, it does not matter whether they are paid according to revenue sharing or to team competition. Finally, if both men and women are employed, the highest performance can be achieved by forming male and female teams and by introducing competition between them. Of course, more evidence is needed to evaluate to what extent these findings can be generalized, for example to other tasks and to larger teams.

\section{References}

[1] Adams, R. B. and Ferreira, D. (2003). Diversity and incentives: Evidence from corporate boards. Stockholm School of Economics. Mimeo.

\footnotetext{
${ }^{18}$ t-test: $p=0.058$, MWU-test: $p=0.08$.

${ }^{19}$ The null hypothesis is that women perform better or equally well under revenue sharing with mixed teams compared to competition of female against male teams (MWU, $p=0.093$ ).
} 
[2] Andreoni, J. and Vesterlund, L. (2001). Which is the fair sex? Gender differences in altruism. Quarterly Journal of Economics, 116, 293-312.

[3] Andreoni, J. and Petrie, R. (2004). Beauty, gender and stereotypes: evidence from laboratory experiments. Mimeo.

[4] Byrnes, J. P., Miller, D. C., and Schafer, W. D. (1999). Gender differences in risk taking: a meta-analysis, Psychological Bulletin 125(3), 367-383 .

[5] Cadsby, C. B. and Maynes, E. (1998). Gender and free riding in a threshold public goods game: experimental evidence. Journal of Economic Behavior and Organization, 34, 603-620.

[6] Conti, R., Collins, M. A., and Picariello, M. L. (2001). The impact of competition on intrinsic motivation and creativity: considering gender, gender segregation and gender role orientation. Personality and Individual Differences, 30, 1273-1289.

[7] Dufwenberg, M. and Muren, A. (forthcoming). Generosity, anonymity, gender. Journal of Economic Behavior and Organization.

[8] Eagly, A. E. and Crowley, M. (1986). Gender and helping behavior: A meta-analytic review of the social psychological literature. Psychological Bulletin 100(3), 283-308.

[9] Eckel, C. C. and Grossman, P. J. (1998). Are women less selfish than men?: Evidence from dictator experiments. Economic Journal 108, 726-735.

[10] Eckel, C. C. and Grossman, P. J. (2001). Chivalry and solidarity in ultimatum games. Economic Inquiry, 39, 171-188.

[11] Eckel, C. C. and Grossman, P. J. (forthcoming). Differences in the economic decisions of men and women: experimental evidence. In: Handbook of Results in Experimental Economics. Edited by C. Plott and V. L. Smith. New York: North Holland. 
[12] Erev, I., Bornstein, G., and Galili, R. (1993). Constructive intergroup competition as a solution to the free rider problem: a field experiment. Journal of Experimental Social Psychology, 29, 463-478.

[13] Ferreira, D. (2002). Group loyalty and incentive pay. U. of Chicago. Mimeo

[14] Gneezy, U., Niederle, M., and Rusticchini, A. (2003). Performance in competitive environments: gender differences. Quarterly Journal of Economics, CXVIII, 10491074.

[15] Hehenkamp, B. and Kaarbøe, O. (2004). Who should receive weaker incentives? Peer pressure in teams. Mimeo.

[16] Huck, S., Kübler, D., and Weibull, J. (2004). Social norms and economic incentives in firms. University of Tilburg Working Paper Series. Mimeo.

[17] Kandel, E. and Lazear, E. (1992). Peer pressure and partnerships. Journal of Political Economy, 100, 801-817.

[18] Mason, C. F., Philips, O. R., and Redington, D. B. (1991). On the role of gender in a noncooperative game. Journal of Economic Behavior and Organization, 15, 215-235.

[19] McBurney, D. H., Gaulin, S. J. C., Devineni, T., and Adams, C.(1997). Superior spatial memory of women: stronger evidence for the gathering hypothesis. Evolution and Human Behavior, 18, 165-174.

[20] Moely, B. E., Skarin, K., and Weil, S. (1979). Sex differences in competitioncooperation behavior of children at two age levels. Sex Roles 5/3: 329-342.

[21] Nalbantian, H. R. and Schotter, A. (1997). Productivity under group incentives: an experimental study. American Economic Review, 87, 314-341. 
[22] Niederle, M. and Vesterlund, L. (2005). Do women shy away from competition? Mimeo.

[23] Nowell, C. and Tinkler, S. (1994). The influence of gender on the provision of a public good. Journal of Economic Behavior and Organization, 25, 25-36.

[24] Ortmann, A. and Tichy, L. K. (1999). Gender differences in the laboratory: evidence from prisoner's dilemma games. Journal of Economic Behavior and Organization, 39, 327-339.

[25] Rapoport, A. and Chammah, A. M. (1965). Prisoner's dilemma: A study in conflict and cooperation. University of Michigan Press. Ann Arbor.

[26] Tottenham, L. R., Saucier, D., Elias, L., and Gutwin, C. (2003). Female advantage for spatial location memory in both static and dynamic environments. Brain and Cognition, 53, 381-383.

[27] van Dijk, F., Sonnemans, J., and van Winden, F. (2001). Incentive systems in a real effort experiment. European Economic Review, 45, 187-214.

[28] Wiley, M.G. (1973). Sex roles in games. Sociometry, Vol. 36, No. 4, 526-541.

\section{Appendix: Instructions}

[translated from German - for revenue sharing (RS)]

Welcome to the experiment! Please read the instructions carefully. If you don't understand something, please raise your hand. We will come to you and answer your question individually. The instructions are the same for all participants.

At the beginning of the experiment you will be randomly matched with a person from the same side of the room. Of course your anonymity will be guaranteed throughout 
the whole experiment. This means that the other participants won't get to know your true identity. The same holds for all participants.

Your task is to solve as many memory games as possible within 15 minutes. As soon as you have solved a game successfully, please announce this by raising your hand. We will then come to you, update your score and start a new game.

Your payoff is determined as follows:

The number of memory games that you solved will be added to the number of solved memory games by the other participant of your group. Each finished game yields one point (= 1 Euro). Each member of the group gets paid half of the joint score.

Example: You have solved X1 and the other member of your group has solved X2 memorygames. Then each of you will be paid $\frac{1}{2}(\mathrm{X} 1+\mathrm{X} 2)$.

At the end of the experiment you are informed about the number of memory games solved by you and by the other member of your group and about your payoff.

At the beginning you will receive an initial endowment of 3 Euros.

If you don't understand something, please raise your hand. We will come to you and answer your question individually.

\section{[translated from German - for team competition (TC)]}

Welcome to the experiment! Please read the instructions carefully. If you don't understand something, please raise your hand. We will come to you and answer your question individually. The instructions are the same for all participants.

At the beginning of the experiment you will be matched with a person from the same side of the room. Of course, anonymity will be guaranteed throughout the whole experiment. This means that the other participants won't get to know your true identity. The same holds for all participants.

Your task is to solve as many memory games as possible within 15 minutes. As soon as you have solved a game successfully, please announce this by raising your hand. We will then come to you, update your score and start a new game. 
Your payoff is determined as follows:

The number of memory games that you solved will be added to the number of solved memory games by the other participant of your group. Each solved game yields one point (= 1 Euro). To determine your payoff the joint score of your group will be compared with the score of another group that consists of persons placed at the opposite side of the room and is randomly matched with your group. In the case that the score of your group is higher, your group will receive a premium of 4 points and the other group will get subtracted 4 points. In the case your group's score is lower than the one of your opponents, your group will get subtracted 4 points while the other one will receive 4 points as a premium. If the scores are the same, neither a premium is paid nor are points subtracted. In any case the payoff of each member of your group amounts to half of the final score of the group.

Put differently, the payoffs are computed in the following way:

You have X1 and the other member of your group has solved X2 memory games. In the other randomly selected group one player has solved Y1 and the other has solved Y2 games.

- If $\mathrm{X} 1+\mathrm{X} 2>\mathrm{Y} 1+\mathrm{Y} 2$ holds, your group will receive a premium of 4 points and the payoff of each group member is $(\mathrm{X} 1+\mathrm{X} 2+4) / 2$.

- If $\mathrm{X} 1+\mathrm{X} 2<\mathrm{Y} 1+\mathrm{Y} 2$ holds, your group will get subtracted 4 points. Therefore each group member receives a payoff equal to $(\mathrm{X} 1+\mathrm{X} 2-4) / 2$.

- If $\mathrm{X} 1+\mathrm{X} 2=\mathrm{Y} 1+\mathrm{Y} 2$ holds, neither a premium is paid nor will points be subtracted. The payoff of each group member is $(\mathrm{X} 1+\mathrm{X} 2) / 2$.

At the end of the experiment you will be informed about how many memory games you and the other participant of your group have solved, and whether you received a premium or whether points were subtracted, as well as your final payoff.

At the beginning you will receive an initial endowment of 3 Euros. In the case of losses, these will be subtracted from your initial endowment.

If you don't understand something, please raise your hand. We will come to you and answer your question individually. 


\section{SFB 649 Discussion Paper Series}

For a complete list of Discussion Papers published by the SFB 649, please visit http://sfb649.wiwi.hu-berlin.de.

001 "Nonparametric Risk Management with Generalized Hyperbolic Distributions" by Ying Chen, Wolfgang Härdle and Seok-Oh Jeong, January 2005.

002 "Selecting Comparables for the Valuation of the European Firms" by Ingolf Dittmann and Christian Weiner, February 2005.

003 "Competitive Risk Sharing Contracts with One-sided Commitment" by Dirk Krueger and Harald Uhlig, February 2005.

004 "Value-at-Risk Calculations with Time Varying Copulae" by Enzo Giacomini and Wolfgang Härdle, February 2005.

005 "An Optimal Stopping Problem in a Diffusion-type Model with Delay" by Pavel V. Gapeev and Markus Reiß, February 2005.

006 "Conditional and Dynamic Convex Risk Measures" by Kai Detlefsen and Giacomo Scandolo, February 2005.

007 "Implied Trinomial Trees" by Pavel Čížek and Karel Komorád, February 2005.

008 "Stable Distributions" by Szymon Borak, Wolfgang Härdle and Rafal Weron, February 2005.

009 "Predicting Bankruptcy with Support Vector Machines" by Wolfgang Härdle, Rouslan A. Moro and Dorothea Schäfer, February 2005.

010 "Working with the XQC" by Wolfgang Härdle and Heiko Lehmann, February 2005.

011 "FFT Based Option Pricing" by Szymon Borak, Kai Detlefsen and Wolfgang Härdle, February 2005.

012 "Common Functional Implied Volatility Analysis" by Michal Benko and Wolfgang Härdle, February 2005.

013 "Nonparametric Productivity Analysis" by Wolfgang Härdle and Seok-Oh Jeong, March 2005.

014 "Are Eastern European Countries Catching Up? Time Series Evidence for Czech Republic, Hungary, and Poland" by Ralf Brüggemann and Carsten Trenkler, March 2005.

015 "Robust Estimation of Dimension Reduction Space" by Pavel Čížek and Wolfgang Härdle, March 2005.

016 "Common Functional Component Modelling" by Alois Kneip and Michal Benko, March 2005.

017 "A Two State Model for Noise-induced Resonance in Bistable Systems with Delay" by Markus Fischer and Peter Imkeller, March 2005.

018 "Yxilon - a Modular Open-source Statistical Programming Language" by Sigbert Klinke, Uwe Ziegenhagen and Yuval Guri, March 2005.

019 "Arbitrage-free Smoothing of the Implied Volatility Surface" by Matthias R. Fengler, March 2005.

020 "A Dynamic Semiparametric Factor Model for Implied Volatility String Dynamics" by Matthias R. Fengler, Wolfgang Härdle and Enno Mammen, March 2005.

021 "Dynamics of State Price Densities" by Wolfgang Härdle and Zdeněk Hlávka, March 2005.

022 "DSFM fitting of Implied Volatility Surfaces" by Szymon Borak, Matthias R. Fengler and Wolfgang Härdle, March 2005.

\section{SFB 649, Spandauer Straße 1, D-10178 Berlin http:/ / sfb649.wiwi.hu-berlin.de}

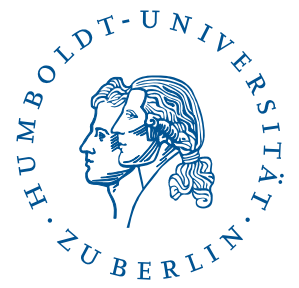


023 "Towards a Monthly Business Cycle Chronology for the Euro Area" by Emanuel Mönch and Harald Uhlig, April 2005.

024 "Modeling the FIBOR/EURIBOR Swap Term Structure: An Empirical Approach" by Oliver Blaskowitz, Helmut Herwartz and Gonzalo de Cadenas Santiago, April 2005.

025 "Duality Theory for Optimal Investments under Model Uncertainty" by Alexander Schied and Ching-Tang Wu, April 2005.

026 "Projection Pursuit For Exploratory Supervised Classification" by EunKyung Lee, Dianne Cook, Sigbert Klinke and Thomas Lumley, May 2005.

027 "Money Demand and Macroeconomic Stability Revisited" by Andreas Schabert and Christian Stoltenberg, May 2005.

028 "A Market Basket Analysis Conducted with a Multivariate Logit Model" by Yasemin Boztuğ and Lutz Hildebrandt, May 2005.

029 "Utility Duality under Additional Information: Conditional Measures versus Filtration Enlargements" by Stefan Ankirchner, May 2005.

030 "The Shannon Information of Filtrations and the Additional Logarithmic Utility of Insiders" by Stefan Ankirchner, Steffen Dereich and Peter Imkeller, May 2005.

031 "Does Temporary Agency Work Provide a Stepping Stone to Regular Employment?" by Michael Kvasnicka, May 2005.

032 "Working Time as an Investment? - The Effects of Unpaid Overtime on Wages, Promotions and Layoffs" by Silke Anger, June 2005.

033 "Notes on an Endogenous Growth Model with two Capital Stocks II: The Stochastic Case" by Dirk Bethmann, June 2005.

034 "Skill Mismatch in Equilibrium Unemployment" by Ronald Bachmann, June 2005.

035 "Uncovered Interest Rate Parity and the Expectations Hypothesis of the Term Structure: Empirical Results for the U.S. and Europe" by Ralf Brüggemann and Helmut Lütkepohl, April 2005.

036 "Getting Used to Risks: Reference Dependence and Risk Inclusion" by Astrid Matthey, May 2005.

037 "New Evidence on the Puzzles. Results from Agnostic Identification on Monetary Policy and Exchange Rates." by Almuth Scholl and Harald Uhlig, July 2005.

038 "Discretisation of Stochastic Control Problems for Continuous Time Dynamics with Delay" by Markus Fischer and Markus Reiss, August 2005.

039 "What are the Effects of Fiscal Policy Shocks?" by Andrew Mountford and Harald Uhlig, July 2005.

040 "Optimal Sticky Prices under Rational Inattention" by Bartosz Maćkowiak and Mirko Wiederholt, July 2005.

041 "Fixed-Prize Tournaments versus First-Price Auctions in Innovation Contests" by Anja Schöttner, August 2005.

042 "Bank finance versus bond finance: what explains the differences between US and Europe?" by Fiorella De Fiore and Harald Uhlig, August 2005.

043 "On Local Times of Ranked Continuous Semimartingales; Application to Portfolio Generating Functions" by Raouf Ghomrasni, June 2005.

044 "A Software Framework for Data Based Analysis" by Markus Krätzig, August 2005.

045 "Labour Market Dynamics in Germany: Hirings, Separations, and Job-toJob Transitions over the Business Cycle" by Ronald Bachmann, September 2005.

\section{SFB 649, Spandauer Straße 1, D-10178 Berlin http:/ / sfb649.wiwi.hu-berlin.de}

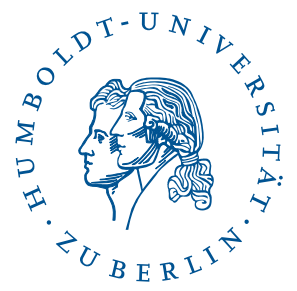


046 "Paternal Uncertainty and the Economics of Mating, Marriage, and Parental Investment in Children" by Dirk Bethmann and Michael Kvasnicka, September 2005.

047 "Estimation and Testing for Varying Coeffcients in Additive Models with Marginal Integration " by Lijian Yang, Byeong U. Park, Lan Xue and Wolfgang Härdle, September 2005.

048 "Zeitarbeit in Deutschland: Trends und Perspektiven" by Michael C. Burda and Michael Kvasnicka, September 2005.

049 "Courtesy and Idleness: Gender Differences in Team Work and Team Competition" by Radosveta Ivanova-Stenzel and Dorothea Kübler, September 2005. 